\title{
Sensitization to Aspergillus Mix Among Atopic Sickle Cell Disease Patients in Abidjan, Côte d'Ivoire
}

\author{
Adou Adjoumanvoule Honoré ${ }^{1}$, Kabore Saydou ${ }^{1,2}$, Dassé Sery Romuald ${ }^{1}$, Yeboah Opong Richard ${ }^{1}$, \\ Goran-Kouacou Amah Patricia ${ }^{1}$, Siransy Kouabla Liliane ${ }^{1,2}$, N'Guessan Koffi ${ }^{1}$, \\ Assi Aya Ursule Aniela ${ }^{1}$, Memel Lasme Roselle Charline ${ }^{1}$, Zaho Ouleon Lea ${ }^{1}$, \\ Yassongui Mamadou Sekongo ${ }^{1,2, *}$
}

${ }^{1}$ Immunology-Allergology Laboratory, UFR-SMA, University Félix Houphouët-Boigny, Abidjan, Ivory Coast

${ }^{2}$ Department of Research, National Blood Transfusion Center, Abidjan, Ivory Coast

Email address:

sekyass@yahoo.fr (Y. M. Sekongo)

${ }^{*}$ Corresponding author

\section{To cite this article:}

Adou Adjoumanvoule Honoré, Kabore Saydou, Dassé Sery Romuald, Yeboah Opong Richard, Goran-Kouacou Amah Patricia, Siransy Kouabla Liliane, N'Guessan Koffi, Assi Aya Ursule Aniela, Memel Lasme Roselle Charline, Zaho Ouleon Lea, Yassongui Mamadou Sekongo. Sensitization to Aspergillus Mix Among Atopic Sickle Cell Disease Patients in Abidjan, Côte d'Ivoire. International Journal of Immunology. Vol. 9, No. 1, 2021, pp. 1-5. doi: 10.11648/j.iji.20210901.11

Received: December 20, 2020; Accepted: December 28, 2020; Published: January 12, 2021

\begin{abstract}
The objective of this study was to determine the epidemiological characteristics of sensitization to Aspergillus in these atopic sickle cell patients who present respiratory disorders unrelated to taking NSAIDs. This is a prospective study with a descriptive and analytical aim which was conducted at the University Hospital Center (CHU) of Cocody (Abidjan). It took place from September 2017 to May 2018 on 117 atopic sickle cell disease patients, with no known history of allergy to aeroallergens, to any foods or to occupational allergens. These patients were interviewed and clinically examined for an atopic site. They were subsequently subjected to skin tests. Statistical analyzes were performed using Epi info 6.0 software using Fisher's test and odds ratio. The significance level was located at an odds ratio greater than 1 . The comparison of the percentages was carried out by Fisher's test with a significance level $p=0.05$. The majority of patients with sensitization to Aspergillus mix were over 15 years of age, with a predominance of women (Sex ratio: 0.56). Neither sex nor age appeared to influence the state of sensitization in our study ( $>0.05)$. The overall prevalence of sensitization to Aspergillus mix was $7.7 \%$. Our results correlated asthma severity with sensitization to Aspergillus mix $(\mathrm{p}<0.05)$. However, there was no significant correlation between severity of allergic rhinitis and sensitization to Apergillus mix. This study confirms the low prevalence of sensitization to Aspergillus mix. Allergy to Aspergillus mix is an uncommon phenomenon in sickle cell patients but its monitoring in this population should be given special attention as it is subject to many complications.
\end{abstract}

Keywords: Sensitization, Aspergillus Mix, Atopic, Sickle Cell Disease

\section{Introduction}

Aspergillus is a ubiquitous mold. There are more than 250 species including Aspergillus fumigatus more frequent in temperate countries, Aspergillus flavus and niger frequently found in tropical countries [1]. Exposure to molds is believed to be associated with the development of allergic respiratory diseases [2, 3], with an overall sensitization prevalence of more than $25 \%$ in atopic and / or asthmatic subjects [4]. In a study on atopic sickle cell disease, authors estimated respiratory manifestations after Non-Steroidal Anti-Inflammatory Drugs (NSAIDs) at $15 \%$. Among them, $5 \%$ of these events were related to NSAIDs, certainly due to immediate hypersensitivity (ISH) [5]. As a result of this allergological survey on this population and in order to identify the cause of these respiratory 
manifestations in the remaining $10 \%$, a series of studies was initiated in order to identify the different allergens to which this population could be sensitized. [6,7]. Thus, in our context of the existence of little data on the actual prevalence of allergic diseases and where fungi are ubiquitous, our objective was to determine the epidemiological characteristics of Aspergillus sensitization in these atopic sickle cell patients who present unrelated respiratory disorders when taking NSAIDs.

\section{Methodology}

This prospective study with descriptive and analytical aims was carried out at the Hospital and University Center (CHU) of Cocody (Abidjan). It lasted 9 months (September 2017 to May 2018).

Our population was selected from among sickle cell patients followed at Cocody University Hospital. 117 atopic sickle cell disease patients were included, with no known history of allergy to aeroallergens, any food allergy, exposure to occupational allergens [8], and who were questioned in search of a ground atopic and clinical examination, then underwent skin testing.

After explaining the principle of the study to the patient or the legal representative, and obtaining their informed consent our patients were subjected to a questionnaire during the consultations preceding the prick-tests (PT). They concerned:

1. The reasons for consultation (asthma, rhinitis, conjunctivitis, digestive signs) with a search for triggering circumstances and ecological factors.

2. The family history of allergic diseases in each patient (ascendants, siblings, descendants): asthma, eczema, conjunctivitis, rhinitis, urticaria, drugs, food.

3. Personal history of atopy: infectious diseases, infant eczema, intolerance to cow's milk, urticaria, angioedema, drug allergy, food allergy, childhood asthma...

4. Personal and / or family history of allergy to possible allergens.

5. The patient's ecological environment.

Clinical and paraclinical explorations (mainly spirometry and chest x-ray) were carried out allowing our patients to be grouped together after 2 clinical pictures: asthma and rhinitis.

The severity of asthma was assessed according to the criteria of the American Thoracic Society (ATS).

The severity of rhinitis was assessed according to the WHO 1999 classification.

The performance of the prick-tests was subject to the following criteria:

1. The absence of any systemic corticosteroid therapy, of any anti-histamine treatment 3 to 10 days before the examination,

2. The absence of beta-blockers, immunosuppressive treatments (tacrolimus, methotrexate, ciclosporin, azathioprine, etc.), eczema flare-up, unstable or severe asthma, an ongoing pregnancy,

At the test site, topical antifungals and topical corticosteroids as well as new topical immunomodulators are discontinued at least one week before testing.

Otherwise, the tests had to be postponed for a substantial period. Patients with dermographism, skin infections, autoimmune diseases, as well as patients whose informed consent was not obtained, were excluded from the study.

As control reactions, we used histamine hydrochloride at $10 \mathrm{mg} / \mathrm{ml}$ for the positive control and phenolic glycerol saline for the negative control. The positive control testifies to the skin reactivity of patients and checks for drug interference, especially antihistamines. The negative control excludes dermographism.

The allergen tested was Aspergillus mix (containing Aspergillus fumigatus, nidulans and niger) which is a commercial extract of STALLERGENE® (Ref. Lot 9710322 $\mathrm{N}^{\circ}$ 7403012). It was systematically performed in the 117 patients participating in this study in strict accordance with the manufacturer's recommendations.

In fact, a drop of the extract was placed on the anterior aspect of the forearm, on healthy skin, free from any skin lesions. A small injection, using a disposable Stallerpoint ${ }^{\circledR}$ type lancet, allowed the allergen to penetrate the superficial dermis, preventing any bloodshed.

Were considered positive, all reactions which resulted in elements of the Lewis triad associated with a papule with a diameter of $50 \%$ of the diameter of the papule of the positive control or greater than or equal to $3 \mathrm{~mm}$ relative to the negative control (reactive). The reading times were set at 20 minutes after the injections performed on the anterior aspect of the forearm.

We calculated the frequencies of allergen sensitization to Aspergillus mix in patients (thanks to the comparison of the percentages) with a significance level $\mathrm{p}=0.05$.

\section{Results}

\subsection{Epidemiological Characteristics of the Studied Population}

\section{Distribution by age}

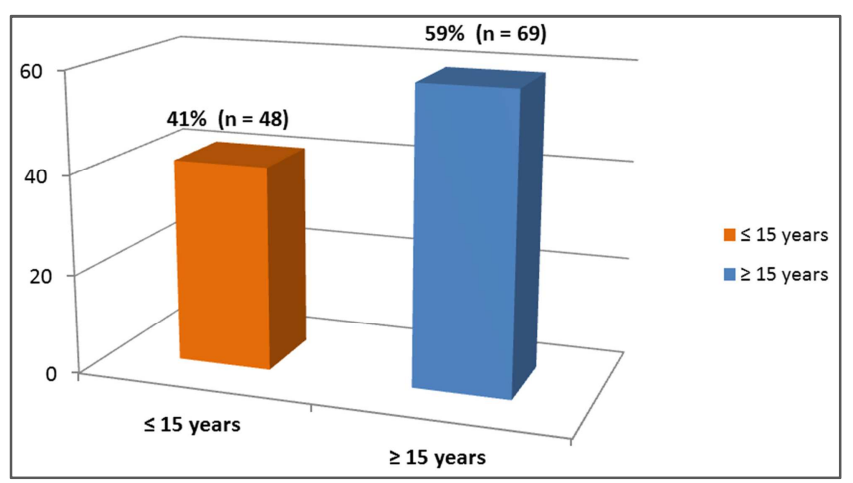

Figure 1. Distribution of patients according to age groups.

The average age of our population was $20.87 \pm 12.8$ years with a predominance of the age group over 15 years. 


\subsection{Distribution by Sex}

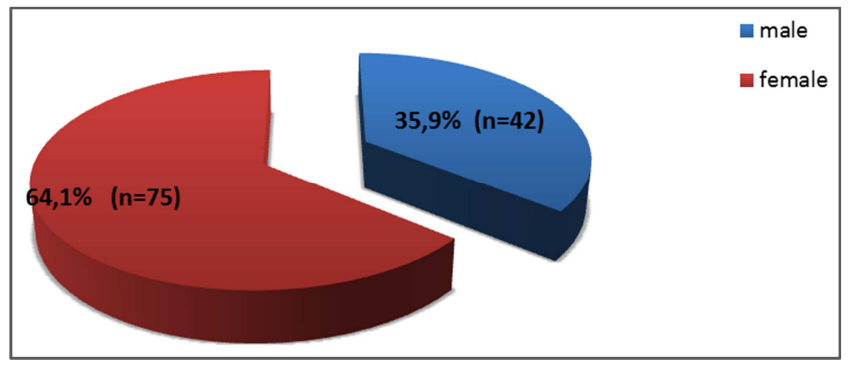

Figure 2. Distribution of the population by sex.

Our study population was predominantly female with a sex ratio of 0.56

\subsection{Global Distribution of the State of Sensitization to Aspergillus Mix}

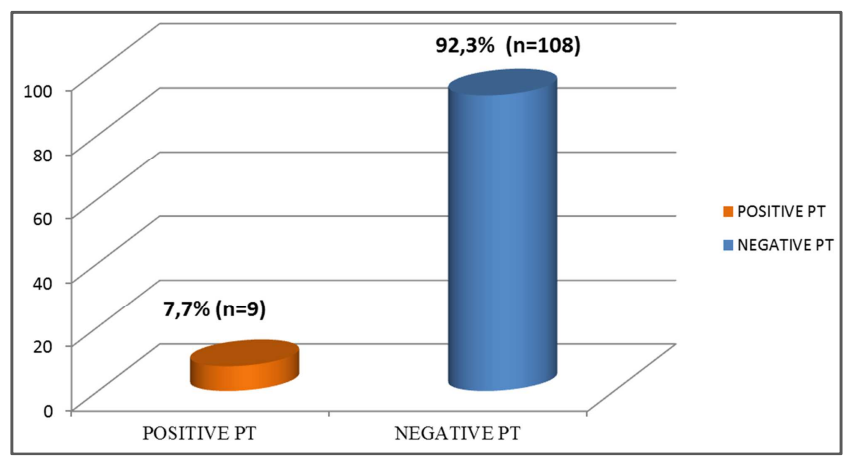

Figure 3. Distribution of patients according to the prick test result $7.7 \%$ of our patients were positive for Aspergillus mix.

\subsection{Aspergillus Mix Sensitization State According to Age and Sex}

Distribution of positive prick tests by age group



Figure 4. Distribution of positive prick tests according to age groups.

Odds Ratio $=1,43(0,3392-6,0161)$ IC 95\%. Fisher exact: $\mathrm{p}=0,45$

Among the 9 patients sensitized to Aspergillus mix 6 were older than 15 years compared to 3 for the age group $\leq 15$ years with non-significant differences $(p>0.05)$

\subsection{Distribution of Positive Prick-tests by Sex}

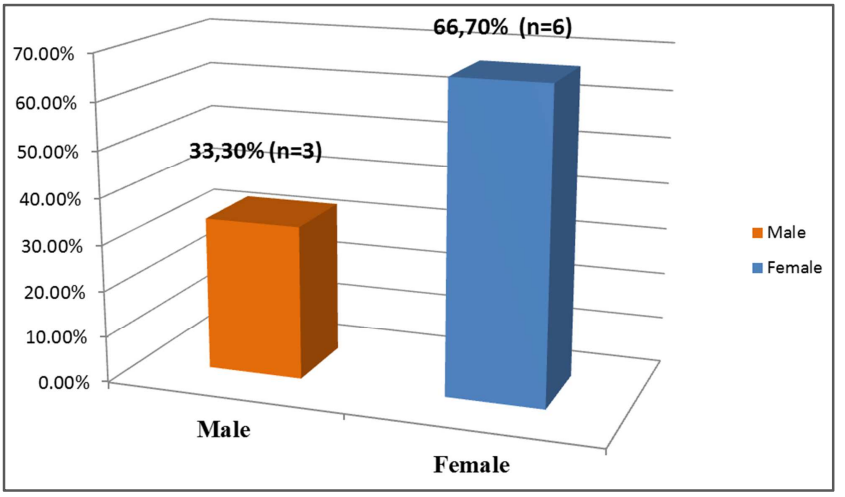

Figure 5. Distribution of positive prick-tests according to gender.

$\mathrm{OR}=0,88 \mathrm{p}=0,59$

$66.7 \%$ of sensitizations to Aspergillus mix were female. The differences observed were not significant $(p>0.05)$

\subsection{Relationship Between the State of Sensitization and Clinical Expression}

\subsubsection{Distribution According to the Occurrence of Asthma in Sensitized Patients (Asthma vs Prick-Test Relationship)}

Table 1. Distribution of patients according to the severity of asthma.

\begin{tabular}{llll}
\hline \multirow{2}{*}{ Asthma $(\mathbf{N}=\mathbf{2 1})$} & \multicolumn{2}{l}{ Prick test for Aspergillus sensibilization } & \multirow{2}{*}{$\mathbf{p}$} \\
\cline { 2 - 3 } & Positive $(\mathrm{n}=\mathbf{3})$ & Négative $(\mathbf{n}=\mathbf{1 8})$ & \\
\hline Moderate to severe $(\mathrm{n}=12)$ & $3(25 \%)$ & $9(75 \%)$ & 0,02 \\
lightweight $(\mathrm{n}=9)$ & 0 & $9(100 \%)$ & 0,86 \\
\hline
\end{tabular}

21 of our patients presented with asthma. 3 patients sensitized to Aspergillus mix presented with moderate to severe asthma

\subsubsection{Distribution According to the Occurrence of Allergic Rhinitis in Sensitized Patients (Asthma vs Prick-test Relationship)}

Table 2. Distribution of patients according to the severity of the allergic rhinitis.

\begin{tabular}{llll}
\hline \multirow{2}{*}{$\begin{array}{l}\text { Rhinite allergique } \\
(\mathbf{N}=\mathbf{8 7})\end{array}$} & \multicolumn{2}{l}{ Prick test for Aspergillus sensibilization } & \multirow{2}{*}{$\mathbf{P}$} \\
\cline { 2 - 3 } & Positive $(\mathbf{n}=\mathbf{9 )}$ & Négative $(\mathbf{n = 7 8 )}$ & \\
\hline Moderate to severe $(\mathrm{n}=60)$ & $6(10 \%)$ & $54(90 \%)$ & 0,11 \\
lightweight $(\mathrm{n}=27)$ & $3(11,1 \%)$ & $24(88,9 \%)$ & 0,14 \\
\hline
\end{tabular}

87 patients had allergic rhinitis. 6 patients sensitized to Aspergillus mix presented with moderate to severe rhinitis.

\section{Discussion}

This present study aims to screen for sensitization to Aspergillus mix including Aspergillus fumigatus, nidulans and niger A. For reasons of feasibility, it was modestly limited to performing skin tests on a target population of 117 patients with atopic sickle cell disease. However, our observations lack research into possible co-sensitizations, 
specific IgE vis-à-vis molecular allergens and recombinant allergens, in particular for A. fumigatus. However, although exhibiting great variability [4], commercial skin test extracts are sensitive tools for diagnosis and essential for the detection of sensitization to molds [9].

Sickle cell disease is a genetic pathology of the red blood cell, which causes systemic functional and tissue damage. It results from a structural and functional $\mathrm{Hb}$ defect called $\mathrm{HbS}$ [10].

Analysis of the distribution of this population by age showed a predominance of adults. Several reasons could explain the low participation of children in our study. We mainly have children's fear of the prick-test technique and invalidation of tests following voluntary discontinuation of the test by children. However, in a study of sensitization to airborne allergens in sickle cell patients in Abidjan, Dasse and al reported prevalences that increased overall with age [11].

Sickle cell disease is a hemoglobin disease that usually starts in childhood. The results of a study carried out on a sickle cell population showed a different distribution from ours with predominance in the youngest [12]. In our series, the majority of patients with sensitization to Aspergillus mix were over 15 years of age, predominantly female. This female predominance is also found by Yamendjé in the same population of sickle cell patients with other allergens. Neither gender nor age seemed to influence the state of sensitization in our study $(\mathrm{p}>0.05)[7]$.

As sickle cell disease is not an autosomal disease linked to sex, our results could be due to the method of selection of our patients during the various consultations, the size of our sample and the high percentage of men in our study.

Elsewhere in Malaysia, Wan Ishlah et al. observed in patients, suffering from allergic rhinitis, sensitization to molds, including Aspergillus flavus (21.2\%), Aspergillus niger (15.3\%), Aspergillus fumigatus (11.8\%), which was not influenced by sex and age [3]

The diagnosis of mold allergy is complicated due to the heterogeneity of the test materials and the decrease in the number of commercial prick test extract solutions that are currently available [9].

In our survey $7.7 \%$ of patients had sensitization to Aspergillus mix. Our results are relatively similar to those of several authors. To My et al. reported 6.5\% sensitization to Aspergillus in pneumallergen skin test results in asthma patients in Viet Nam [13]. Dézfoulian et al. revealed 5.9\% sensitization to Aspergillus mix in 68 patients in a comparative study [14]. However, other authors have obtained different levels of awareness from ours. In a series on mold allergy in Tunisia, Abouda et al. communicated 14.9\% awareness of Aspergillus [15]. Kongpanichkul et al. reported 2\% sensitization to Aspergillus mix in 100 Thai children with asthma [16]. These different results do not differ too much from the prevalence obtained in circumstances of occupational exposure indicating the ubiquitous nature of the Aspergillus fungus: $6 \%$ and $9 \%$ sensitization to aspergillus mix respectively in Morocco [8] and Poland [17].
Sensitization to fungi is reported to correlate with asthma [18]. Our results support the data in the literature by establishing a relationship between the severity of asthma and sensitization to Aspergillus mix ( $p<0.05)$. Indeed, Tanaka et al. reported in patients sensitized to Aspergillus, a risk factor for severity of asthma, and this sensitization was linked to an increased risk of poor asthma control [19]. In Morocco, in a study that investigated the correlations between asthma control and skin sensitization to molds, Bopaka et al. documented $39 \%$ skin sensitization to A. fumigatus in 44 asthmatic patients with associated rhinitis [20]. Sensitization to molds, including Aspergillus, correlated with the severity of asthma was similarly described by Hayes and al [21].

Exposure and sensitization to fungal allergens may promote the development and aggravation of allergic rhinitis [22]. However, we noted that there was no significant relationship between the severity of allergic rhinitis and sensitization to Aspergillus mix. This could be due to the restricted nature of our allergenic extract. Likewise, in Turkey, Ozturk et al. found a significant difference in the severity of allergic rhinitis in elderly people exposed to aeroallergens, including $8 \%$ sensitization to Aspergillus fumigatus [23].

\section{Conclusion}

These results remain specific to the sickle cell population. However, they merit further investigation with other population samples to better appreciate the locoregional prevalence of Aspergillus sensitization. In addition, a representative sample of other clinical profiles, involving multi-center centers in Côte d'Ivoire and the sub-region will allow for a better discussion of the relevance of Aspergillus awareness raising. Since sickle cell disease is subject to many complications, careful monitoring of these subjects is very important.

\section{Declaration of Links of Interest}

The authors declare that they have no links of interest.

\section{Conflict of Interest}

The authors declare that they have no competing interests.

\section{Authors' Contribution}

All the authors attest to having contributed to the realization and the writing of this work

\section{References}

[1] Agarwal R. Allergic Bronchopulmonary Aspergillosis. Chest. Mar 2009; 135 (3): 805-826. 
[2] Arikoglu T, Batmaz SB, Coskun T, Otag F, Yildirim DD, Kuyucu S. The characteristics of indoor and outdoor fungi and their relation with allergic respiratory diseases in the southern region of Turkey. Environ Monit Assess. 2016; 188 (6): 380.

[3] Wan Ishlah L, Gendeh BS. Skin prick test reactivity to common airborne pollens and molds in allergic rhinitis patients. Med J Malaysia. 2005; 60 (2): 194.

[4] Kespohl S, Maryska S, Zahradnik E, Sander I, Brüning T, Raulf-Heimsoth M. Biochemical and immunological analysis of mould skin prick test solution: current status of standardization. Clin Exp Allergy. 2013; 43 (11): 1286-96.

[5] Dassé SR, N'Guessan K, Akré DP, Yao R, Sombo MF. Pulmonary events induced by non-steroidal anti-inflammatory drugs in patients with sickle cell disease. Santé. 2011; 21 (4): $187-91$

[6] A. H. Adou, L. Siransy, R. Yeboah, A. P. Kouacou, K. N'Guessan, R. Dassé. État de sensibilisation allergénique au café et au thé chez le drépanocytaire atopique. Revue française d'allergologie, 2017; 57 (5): 356-363.

[7] Yamendjé TS. Etude de l'état de sensibilisation à Dermatophagoïdes pteronyssinus chez les drépanocytaires suivis au Service d'Immunologie et Hématologie du CHU de Cocody [Mémoire de Certificat d'Etudes Spéciales d'Immunologie générale et médicale]. Abidjan: Université Félix Houphouët Boigny UFR des Sciences Médicales; 2013. $\mathrm{N}^{\circ} 2133$.

[8] Laraqui Hossini $\mathrm{CH}$, Rahhali AE, Laraqui Hossini O, Lekhssassi S, Verger C, Caubet A. Prévalence des symptômes respiratoires, des troubles ventilatoires et des sensibilisations cutanées à différents allergènes chez les épiciers de Casablanca. Revue Française d'Allergologie et d'Immunologie Clinique. 2002; 42 (8): 769-778.

[9] Kespohl S, Maryska S, Bünger J, Hagemeyer O, Jakob T, Joest $M$ and al. How to diagnose mould allergy? Comparison of skin prick tests with specific IgE results. Clin Exp Allergy. 2016; 46 (7): 981-91.

[10] Huynh-Moynot S, Moynot JC, Commandeur D, Danguy Des Desrts M, Montelscaut E, Kenane N et al. Drépanocytose: des aspects moléculaires à la pratique clinique. À propos d'un cas et revue de la littérature. Annales de Biologie Clinique. 2011; 69 (6).

[11] Dasse S, Siransy L, Yeboah R, Adou H, Koffi N, Kouakou P et al. État de sensibilisation aux allergènes aéroportés chez le drépanocytaire à Abidjan - Côte d'Ivoire. Revue Française d'Allergologie. 2016; 56 (3): 283.

[12] Krizo GA. Fréquence des hémoglobines anormales en Côte
d'Ivoire de janvier 1999 à juin 2009.[Mémoire de Certificat d'Etudes Spéciales d'Hématologie-Biologie]. Abidjan: Université Félix Houphouët Boigny UFR des Sciences Médicales; 2009. № 2061.

[13] To My H, Raffard M. Résultats des tests aux pneumallergènes chez des asthmatiques à Ho Chi Minh ville-Viet Nam. J Fran Viet Pneu 2011; 02 (05): 1-92.

[14] Dézfoulian B, De la Brassinne M. Étude comparative des «prick» et «patch» tests aux moisissures, aux dermatophytes et aux levures dans la dermatite atopique de la tête et du cou, la dermatite séborrhéique et le sébopsoriasis. Revue Française d'Allergologie et d'Immunologie Clinique. 2005; 45 (5): 376384 .

[15] Abouda M, Yangui F, Khouani H, Triki M, Charfi MR. L'allergie aux moisissures en Tunisie. Revue française d'allergologie. 2014; 54: 265-275.

[16] Kongpanichkul A, Vichyanond P, Tuchinda M. Allergen skin test reactivities among asthmatic Thai children. Journal of the Medical Association of Thailand. 1997; 80 (2): 69-75.

[17] Wiszniewska M, Walusiak-Skorupa J, Pannenko I, Draniak M, Palczynski C. Occupational exposure and sensitization to fungi among museum workers. Occup Med (Lond). 2009; 59 (4): $237-42$.

[18] Bissinger I, Bareño J. Clinical profile of sensitization to fungi in Medellin, Colombia. Rev Alerg Mex. 2016; 63 (2): 123-34.

[19] Tanaka A, Fujiwara A, Uchida Y, Yamaguchi M, Ohta S, Homma $\mathrm{T}$ and al. Evaluation of the association between sensitization to common inhalant fungi and poor asthma control. Ann Allergy Asthma Immunol. 2016; 117 (2): 163 168 .

[20] Bopaka RG, El Khattabi W, El Bied B, Choubi M, Aichane A, Afif H. Corrélations entre contrôle de l'asthme et sensibilisation cutanée aux moisissures. Revue Française d'Allergologie, 2015; 55 (8): 517-520.

[21] Hayes D Jr, Jhaveri MA, Mannino DM, Strawbridge H, Temprano J. The effect of mold sensitization and humidity upon allergic asthma. Clin Respir J. 2013; 7 (2): 135-44.

[22] Kołodziejczyk K, Bozek A. Clinical Distinctness of Allergic Rhinitis in Patients with Allergy to Molds. Biomed Res Int. 2016; 2016: 1-6.

[23] Ozturk AB, Ozyigit LP, Olmez MO. Clinical and allergic sensitization characteristics of allergic rhinitis among the elderly population in Istanbul, Turkey. Eur Arch Otorhinolaryngol. 2015; 272 (4): 1033-5. 